\title{
Hegemoni Ideologi Konsumtif sebagai Gaya Hidup Remaja
}

\section{Hegemony of Consumptive Ideology as a Youth Lifestyle}

\author{
Yofiendi Indah Indainanto $\left(^{*}\right)$ \\ Magister Ilmu Komunikasi, Universitas Diponegoro, Indonesia
}

Diterima:18 Maret 2020; Disetujui: 18 April 2020; Dipublish: 27 April 2020

*Coresponding Email: yofiendi@gmail.com

\begin{abstract}
Abstrak
Media baru memberikan pengaruh kuat dalam membentuk pengetahuan dan karakter remaja sebagai kelompok kelas menengah. Kemasan konten direpresentasikan senatural mungkin dalam menamkan pengaruhnnya, sehingga terjadi prakek hegemoni. Konten-konten yang menekankan dan menonjolkan budaya konsumtif dijadikan andalan untuk menarik perhatian penonton melalui chanel Youtube untuk meningakatkan jumlah viewer untuk mendapatkan keuntungan. Praktik ini yang membuat hegemoni konsumtif membuat penonton mengalami persetujuan. Studi ini mendiskripsikan bagaimana proses hegemoni dalam membentuk ideologi konsumtif, menggunakan studi kualitatif dengan pendekatan literatur untuk memperkuat penjelasan hegemoni Gramsci. Objek analisis chanel Youtube Ria Ricis official dengan tema konten belanja warna-warni dan Squsihy. Hasil menunjukan akun tersebut mengemas konten dengan menumbuhkan efek kesenangan dalam menekankan ideologi konsumtif dan menggunggah konten serupa dengan tema sama karena adanya persetujuan.. Media sosial memberikan kedekatan antara audiens dan pemilik konten sehingga praktek hegemoni dengan mudah mengalami persetujuan. Dalam mempertahankan ideologi konsumtif, kelompok dominan melakukan representasirepresentasi yang memungkinkan mendatangkan respon baik. hegemoni tersebut membuat ideologi konsumtif berkembang menjadi gaya hidup.

Kata kunci: Hegemoni, Ideologi konsumtif, Youtube, Media Sosial
\end{abstract}

\begin{abstract}
The new media provides a powerful influence in shaping the knowledge and character of adolescents as a middle class group. Content packaging is represented as naturally as possible in capturing its influence, so that a hegemony practice takes place. Content that emphasizes and accentuates consumptive culture is used as a mainstay to attract the attention of audiens through Youtube channel to increase the number of viewrs to gain profit. This practice is what makes consumptive hegemony make audines subject to approval. This study describes how the practice of hegemony in shaping consumptive ideology, uses qualitative studies with a literary approach to strengthen Gramsci's hegemony explanations. Ria Ricis official Youtube channel analysis object with colorful and squsihy shopping content themes. The results show that the account packages content by cultivating the effect of pleasure in emphasizing consumptive ideology and uploading similar content with the same theme because of the approval. Social media provides a closeness between audiens and content owners so that the practice of hegemony is easily subjected to approval. In defending consumptive ideology, the dominant group makes representations that allow good responses. the hegemony made the consumptive ideology develop into a lifestyle.

Keywords: Hegemony, Consumptive ideology, Youtube, Social Media
\end{abstract}

How to Cite: Indainanto, Y.I (2020). Hegemoni Ideologi Konsumtif sebagai Gaya Hidup Remaja. Jurnal Simbolika: Research and Learning in Comunication Study 6(1): 65-75 


\section{PENDAHULUAN}

Interaksi yang tinggi di media sosial berdampak pada tingginya informasi yang berkembang, sehingga tidak sedikit orang berlomba-lomba menampilkan informasi untuk kebutuhan tertentu, baik berupa ajang aktualisasi diri, eksistensi diri, bisnis, dan mencari informasi. Media sosial seperti Youtube menyebapkan logika dan pola pikir manusia dalam mengonsumsi, hal itu karena adanya dorongan aktif individu untuk mengkonsumsi konten yang diinginkan. Dampak positif dalam adanya hegemoni melalui media sosial mampu mengetahui perkembangan tentang barang dan gaya hidup terkini. Selain pengetahuan tentang informasi tinggi. Dampak negatif adanya hegemoni gaya hidup akan mendorong seseorang mengonsumsi barang, atau gaya hidup yang ditontonnya untuk kebutuhan kepuasan dan kesenangan yang disepakan pengaruh konten dalam mempengaruhi audies. Mendapatkan prestise dari orang lain merupakan salah satu bentuk budaya konsumsi.

Akun Youtube Ria Ricis sejuah ini telah memiliki 17,5 juta subscriber dan telah mengunggah ratusan video berbagai tema diakun miliknya. Ria Ricis sebagai salah satu publik figur dikanal sangat menginpirasi kalangan muda melalui chanel Youtubenya. Melalui aktivitas sehari-harinya dan identitas humoris telah banyak membuat konten yang memberikan konsep dan gaya baru kehidupan yang menyenangkan. Berdasarkan pengakuannya melalui video yang diunggah, Subscribernya dididominasi kalangan remaja sebagai penikmat konten. Artinya remaja sangat menyukai apa yang disampaikan Ria Ricis. Pengamatan berbagai konten yang dominan, Ria Ricis ada kecenderungan membangun konten yang berakitan dengan budaya hedonisme, seperti konten review makanan, tempat, berbelanja dan mengenalkan fashion terkini. Tidak tanggung-tanggung gaya hidup mewah dalam keseharian yang ditampilkan membentuk konsep ideal bagi seorang wanita yang mampu mendorong orang untuk mengikuti gayanya. Melalui video vlog, Ria membuat konten dengan memanfatkan berbagai properti, kekayaan dan orang-orang disekelingnnya, dengan kemasan santai, keseharian, dan humoris.

Ideologi konsumtif ditanamkan senatural mungkin agar penonton dapat melihat itu sesuatu yang dekat dengannya dan kesannya tidak dibuat-buat salah satu contohnya dengan menampilkan dalam bentuk kehidupan sehari-hari yang dengan kehidupan masyarakat umum. Video yang didominasi tentang pola konsumtif, sangat dominan terlihat dalam unggahnnya. Banyyak penelitian yang melihat Youtube digunakan untuk memberikan pengaruh terhadap penontoonnya. Seperti, Studi yang dilalukan Rumondang Eliza Maria Sinaga dan Andriani Kusumawati (2018) tentang pengaruh Youtube Beauty Vlogger Pengguna Kosmetik Maybelline terhadap minat dan keputusan membeli menunjukan hasil yang singnifikan. Hal senada juga ditemukan Eribka Ruthellia, David Mariam Sondakh dan Stefi Harilama (2017), bahwa konten vlog membentuk sikap positif berupa ingin mencoba dan berkinginan menjadi vloger. Sementara itu, studi Ranti Tri Anggraini dan Fauzan Heru Santhoso (2017) menemukan ada hubungan positif antara gaya hidup hedonis dengan perilaku kosnsumtif pada remaja. Media Youtube berperan signifikan dalam membentuk gaya konsumtif 
terhadap remaja. Remaja akan mudah terpengaruh didasari pada mental keperibadian yang belum "matang" sehingga mudah menerima sesuatu yang baru. Oleh sebap itu, dalam artikel ini tujuan penelitian untuk mendiskripsikan bagaimana hegemoni yang dilakukan Ria Ricis dalam membentuk idelologi konsumtif sebagai gaya hidup remaja, melalui analisi video.

Pandangan hegemoni menurut Gramsci menekankan pada bentuk ekspresi, cara penerapannya, mekanisme yang dijalankan untuk mempertahankan dan mengembangkan diri terhadap kepatuhan terhadap korbannya yang akhirnya membentuk pola pikir (Eriyanto, 2011).

Gramsci menjelaskan bahwa dalam membentuk konsensus seperti apa yang diinginkan, kelas tertentu biasanya menggunakan mekanisme kelembagaan sebagai transmisi. Media adalah salah satu mekanisme kelembagaan itu, yang menurut Gramsci sebagai "tangan-tangan" kelompok yang berkuasa untuk menentukan ideologi yang mendominir (Mahdi, 2015). Hegemoni diproduksi melalui praktik-praktik yang dilakukan media, memanfaatkan para aktor untuk menciptakan konten-konten media yang akan mempertahankan sebuah ideologi konsumtif. Hegemoni digunakan untuk menggambarkan jenis kekuatan tertentu yang muncul dari merangkul seluruh kecenderungan ideologis media massa untuk mendukung sistem kekuasaan yang mapan dan mengecualikan nilai oposisi dan persaingan (Oktavianti, 2018). Kemasan konten menjadi andalan dalam membentuk kesadaran palsu yang dilakukan media untuk membentuk

dominasi tanpa adanya paksaan. Meskipun pada dasarnya penonton memiliki ideologi tertentu ketika menonton, namun bentuk hegemoni yang halus dan kekuasaannya terbatas, membuat penonton tidak sadar bahwa mereka sedang terhegemonik sehingga terkesan natural. Berbeda kasus ketika penonton berada pada kalangan kelas menengah atau remaja yang masih rentan ideologinya, mereka akan mengganggap apa yang diproduksi aktor, seakan-akan mewakili jiwa mereka, sehingga ideologi tersebut dianggap benar.

\section{METODE PENELITIAN}

Artikel ini menggunakan metode diskriptif kualiatif dengan pendekatan analisis wacana model Teun A Van Dijk. Diskriptif kualitatif digunakan untuk menjelaskan representasi hegemoni dalam teks. Model Teun A Van Dijk digunakan untuk melihat teks memiliki struktur wacana tentang bagaimana teks menegaskan suatu tema. Struktur teksnya, Pertama, struktur makro merupakan makna umum yang dapat diamati dari topik/tema. Kedua, Superstruktur merupakan kerangka teks, seprti pendahuluan, isi, penutup, dan kesimpulan. Ketiga, Struktur Mikro merupakan makna lokal dari suatu teks yang dapat diamati dari pilihan kata, kalimat dan gaya yang dipakai. (Eryanto, 2011). Kerangka analisis dalam penelitian ini hanya berfokus pada teks yang ditampilkan dalam Video chanel Youtube Ria Ricis Official dengan tema konten belanja warna-warni dan squsihy objek. Teori hegemoni dari Gramsci digunakan untuk membongkar teks yang ditampilkan dalam membentuk ideologi konsumtif 
yang dilakukan melalui proses persetujuan.

\section{HASIL DAN PEMBAHASAN}

\section{Pembentukan Ideologi Konsumtif} Sebagai Gaya Hidup

Struktur Teks. Konten Squsihy dan belanja menjadi tema yang diangkat dalam memberikan penonjolan dari sebuah peristiwa. Tema-tema seperti ini, memiliki daya tarik tersendiri bagi remaja karena memiliki keunikan dan perhatian lebih karena bentuk menarik dan sangat dekat dengan remaja terutama perempuan. Seperti dalam video "Unboxing Squishy Senilai Rp 3000000 ! Part 1". Bagian pertama video menujukan model-model Squishy dengan berbagai warna, kemudian harga setiap unit. Adanya video ini didukung rentetan video dengan tema serupa dengan ciri pembeda dari nominal harga yang ditampilkan. Artinya, meskipun ada informasi harga yang mahal, namun dijadikan strategi untuk menarik penonton untuk menyaksikan tema serupa divideo lain. Penekanan akan memberikan Squishy seperti dalam teks:

"Temen-temen karena ini totalnya senilai Rp 3 juta, Ricis mau tanya kekalian, jika kalian disuruh memilih uang cas 3jt atau atau Squishy senilai 3jt kalian boleh komen dibawah yang mana akan dipilih". Menjadi bagian yang tidak terpisahkan, agar penonton terus mengikuti video lain.

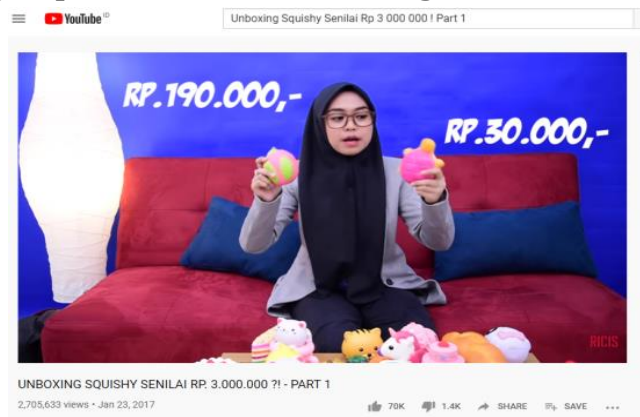

Gambar 1. Ria menunjukan harga, dan bentuk Squishy
Situasi video yang mengasikan dengan kemasan humor ditambah dengan adanya Squishy dengan karakter-karakter lucu, boneka, hewan, kue, dan makanan, menjadikan suasanan menjadi santai. Situasi seperti ini banyak disenangi anak muda. Gaya hidup tidak terlepas dari apa yang disenangi oleh seseorang, sehingga akan mempengaruhi dalam mengambil pengetahuan dan keputusan. Latar seperti itu berusaha direperesentasikan Ria untuk memberikan kuasanya. Dalam mendukung kuasanya, Ria menonjolkan warna-warna cerah, karakter unik, pembawaan humoris dan interkasi dengan pengguna.

Konten video belanja menjadi tema yang menojol dalam akun Youtube. Pemilihan Judul video menggunakan "belanja sepuasnya" menjadi kata yang sering digunakan dalam judul, seperti "Belanja Lol Surprise Sepuasnya Sampai Tutup!! Surprise Maryam $\odot$ ", dan "24 Jam Makan Yang Warna Biru Terbanyak SeIndonesia...". Penekanan pada kedua video bagaimana keasikan dalam berbelanja lebih utama dibanding dengan nilai guna dari barang. Isi video pertama momen belanja Ria yang dengan kedua temannya untuk memberikan kado. Isi video kedua bercerita berbelanja setiap barang dengan warna biru lalu mengkonsumsi, ", kita akan seharian bersama warna biru, ..sekarang kita mau cari alat dan bahan-bahan semuanya yang berwarna biru..". Praktis kedua video menjadikan belanja sebagai hiburan dan memburu kesenangan, terlihat dari nilai guna dan kebutuhan yang sangat berbeda ditampilkan dalam video. Situasi video yang didominiasi saat belanja, memberikan fokus perhatian pada proses belanja yang ditampilkan, sehingga maksud dari video menunjukan bagaimana belanja itu memberikan kesenangan. 
Proses Hegemoni. Hegemoni memiliki berbagai kekuatan untuk mempengaruhi masyarakat. Salah satu bentuk kekuatan hegemoni adalah adanya kemampuan untuk menciptakan cara berpikir atau wacana tertentu yang dominan, dianggap benar sehingga masyarakat meyakini wacana tersebut sebagai sesuatu yang benar juga sebaliknya sebagai sesuatu yang salah atau menyimpang (Juditha, 2018), seperti kegunaan Squishy sebagai sarana untuk melampiaskan keresahan.

"Yah, bisa menghilangkan stres, boring, tinggal pencet-pencet, kalu lagi emosi marah sama siapapun gk perlu keorangnya.." isi video Unboxing Squishy Senilai Rp 3000000 ! Part 1. Artinnya dalam pandangan media maxis klasik yang menyebut media masa menyebarkan gagasan dan pandangan kelas penguasa yang menghasilkan false conscious (kesadaran palsu), produk-produk media merupakan cerminan nilai-nilai kelas pengusaha (Kellner, Hainsworth, \& Hall, 2003). Bagi remaja yang termasuk kelompok menengah dimana terdapat proses mencari jati diri, jika hegemoni ini terus terjadi dalam waktu lama, maka akan membentuk pengetahuan dan sikap.

Strategi hegemoni dalam Unboxing Squishy Senilai Rp. 3.000.000 ?! - Part 1 terlihat menunjukan detail konten.. Menceritakan karakter Squishy, merupakan upaya menghegemoni untuk menanamkan kosep pengetahuan penonton, sehingga memunculkan dorongan untuk memilki. Strategi tersebut sejalan dengan asumsi teori Gramsci yang menyebut kekuatan fisik bukanlah yang utama karena kekuatanya terbatas, namun penguasaan ide dan sarana penyebaranya lebih penting. Supaya terhegemoni, kelompok akan merasa memiliki dan merasakan nilai serta norma penguasa (Dimyati, 2014). Persetujuan melibatkan kondisi mental yang kompleks, sebuah kontradiktif kesadaran antara pencampuran persetujuan dan apatis, perlawanan dan pengunduran diri (Lears, 2016).

Berbeda dengan video tentang belanja, Ria secara langsung menanamkan konsep konsumtif dengan berbelanja makanan dengan warna tertentu, hal tersebut diperkuat peran anak-anak dalam video belanja makanan warna biru, dengan konsep gerakan sosial membantu Ria memasukan makanan yang dibalas Ria dengan membayar belanjaan menumbuhkan jiwa sosial penonton.

"seneng sama anak zaman sekarang milenial ringan tangan saling membantu, itu kenapa Ricis sangat senang memotiviasi anak-anak di Indonesia", video 24 Jam Makan Yang Warna Biru Terbanyak SeIndonesia..

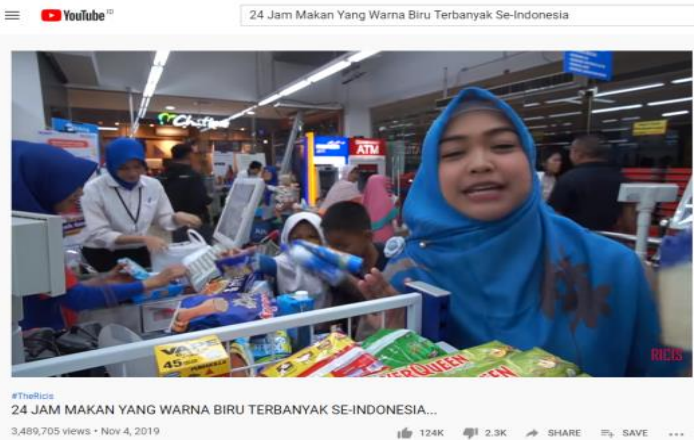

Gambar 2. Ria yang dibantu anak-anak Adegan tersebut memberikan wacana, bahwa video terihat natural tanpa drama. Karanter cerita seperti ini efekti digunakan dengan cerit keseharian. Ajakan untuk berbelanja juga ditekankan secara langsung, "kita belanjanya di Naga Swalayan, deket rumah aku, buat tementemen yang mau cari apa aja, main ke Naga 
Swalayan karena semuanya lengkap,". Pemilihan belanja warna-warna dijadikan untuk membentuk dominasi pengetahuan dan identitas kuasa.

Belanja makanan umumnya merupakan sesuatu yang alamiah dialami semua orang untuk memenuhi kebutuhan, berbeda dalam adegan video, berbelanja untuk memenuhi konten yang merubah nilai guna menjadi nilai tukar, dan ada ajakan untuk beberlanja di lokasi. Agar ajakan tersebut tidak terkesan iklan, beberapa kali Ria menekankan pada lokasi yang "dekat rumah", artinnya penonton konsensus tanpa memandang itu iklan bisa melakukan hal serupa dimanapun.

Adanya video tersebut mendorong dominasi konten untuk menanamkan budaya konsumtif, menjadi bagian dari keseharian. Hegemoni memanipulasi sistem kepercayaan kolektif untuk menanamkan pandangan dunia yang masuk akal. Artinnya subyek mengadopsi posisi ideologis dan membuat pilihan yang mereka anggap sesuai dengan kepentingan terbaik meskipun bertentangan kesejahteraan mereka namun tetap tunduk pada kelas dominan karena ideologis atau pandangan dunia yang masuk akal masuk karena dikemas senatural mungkin (Jaques, Islar, \& Lord, 2019). Budaya belanja menjadi pilihan yang diangap benar dalam memberikan kesenangan dan menghilangkan batas-batas kebutuhan dari nilai suatu barang.

Chanel Youtube Ria Ricis memberikan pleasure kepada penonton untuk melihat konten-konten yang mendatangkan selera humor dan senang. Pada dasarnya, menonton video Ria, sebenarnya tidak jauh berbeda dengan melihat konten produk. Video-video yang bersifat "hiburan" tetap memiliki rekomendasi produk-produk tertentu seperti yang mengarahkan pada belanja di Naga Swalayan tempat berbagai produk dijual, terlihat pada video, "24 Jam Makan Yang Warna Biru Terbanyak Se-Indonesia...".

Munculnya advertorial (gabungan iklan dengan editorial, mampu mengkamuflase iklan suatu produk, seakan-akan itu adalah konten. Penekanan seperti close up produk yang dibeli.

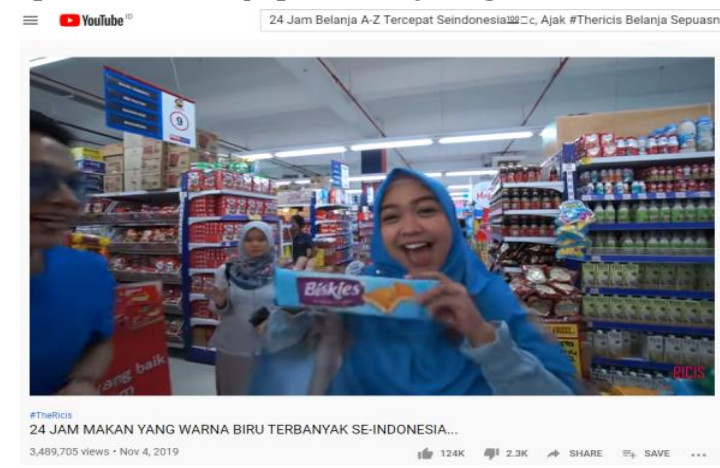

Gambar 3. Ria sedang menunjukan produk berwarna biru

Bahkan video tentang belanja tidak ada bedanya dengan publikasi berisi kumpulan iklan. Wajar penonton tidak merasa apa yang dilihat adalah kumpulkan iklan, karena Ria Ricis mampu mengarahkan perhatian penonton pada dirinya dan aktor lain. Pada dasarnya apa yang dilakukan Ria Ricis untuk menghasilkan keuntungan yang signifikan dari Youtube itu sendiri. Tentu Ria tidak bisa mendapatkan keuntungan hanya dari Youtube, melainkan pengiklan yang akan mendatangkan keuntungan besar. Budaya seperti itu terus dipraktekan dalam kehidupan sosial dimaknai, diproduksi, disirkulasi, dan dipertukarkan, (Thwaites etal 1994) dalam (Ida, 2018), sehingga jika budaya dikonteksualkan dalam teks akan memperkuat kedudukannya. Selama ideologi diterima sebagai kebutuhan untuk mengatur dan mengarahkan massa manusia, maka memiliki psikologis validitas dan tentukan kesadaran yang 
memiliki efek jangka panjang dalam hubungan struktural (Daldal, 2014). Artinya konten-konten yang menekankan budaya konsumtif akan berdampak pada pembentukan pisikologis yang mengarah pada kebutuhan pada pada gaya hidup. Bagi kelompok kelas menengah, akan rentan mengalami perubahan dari apa yang dikontruksikan melalui media.

\section{Media Membangun Kedekatan.}

Konten yang jauh dari realitas akan membuat penonton tidak nyaman dengan konten. cara membangun kedekatan dengan realita sehingga seakan-akan natural seperti apa yang dikatakan Bonnie Wiscarson (Estiani, 2012), pertama improve kehidupan mereka, dan juga diri mereka sendiri dengan cara mementuk gaya hidup yang mampu mengekspresikan diri, dan gaya konsumtif dalam konten. Penggambaran belanja dengan sangat mudah dilakukan tanpa ada pertimbangan, sehingga dengan mengkonsumsi akan mampu mendatangakan kesenangan. Cara yang kedua adalah dengan menawarkan fantasi atau mimpi. Fantasi ini bisa ditunjukkan melalui imajinasi yang "sempurna". Tema fantasi didramatisasi menjadi rantai fantasi yang mengingkatkan intensitas dan kegairahan partisipan komunikasi dan mendapatkan fans atau follower yang menciptakan terbangunnya simbol-simbol hasil pertukaran pesan melalui fantasi setiap unggahan dari generasi milenial sebagai bentuk representasi cara pikir dan pandang tentang dunia (Mutiaz, 2019). Akun Ria Ricis Menggambarkan gambaran wanita muda dan religius yang didukung dengan kemewahan. Artinya mampu menggambarkan fantaasi wanita yang cantik, muslim, humoris dan memiliki kekayaan termasuk mengkonsumsi barang. Dukungan lingkungan yang indah seperti interior rumah mewah, mobil dan kedekatan dengan artis, penonton merasa ingin menjadi seperti Ria, hal tersebut mampu membangun fantasi bagi penonton dan menginginkan berada disituasi yang sama.

Cara ketiga adalah melalui "nature" atau "sifat dasar" dari konsumsi itu sendiri. Bawah konsumsi orang akan barang dan kebutuhan tidak akan sama dalam setiap waktu, dan terus berganti, sehingga Ria Ricis selalu mengganti bentuk konsumsi yang dilakukan melalu konten. Cara tersebut dijadikan kekuatan dalam menguatkan ide-ide tentang kekuasaan yang mampu memotiviasi orang untuk berfikir menghasilkan ide-ide dalam sudut pandangan berbeda, kekuasaan itulah yang dijadikan simbol bagi orang yang menghegemoni (Mora, 2014).

Kelas menengah adalah kelompok orang yang meraih sukses karena memiliki disiplin tinggi, mandiri (independent), mematuhi ketentuan-ketentuan berlaku, dan memberi sumbangan berarti melalui karya (Heryanto, (2000) dalam Kertamukti, Nugroho, \& Wahyono, 2018). Kelas menengah yang diidentikan dengan remaja dengan kondisi mental dan pengetahuan yang belum matang, rawan terhegemoni karena belum memiliki pondasi kuat, sehingga ketika media menawarkan fantasi atau mimpi itu dianggap mampu mewakli jiwanya. Video Ria Ricis memberikan penonton kelas menengah bisa mengetahui, mengenal, dan merasakan gaya hidup yang ideal atau mewakili kelas atas yang diidentikan dengan kematangan. 
Mengonsumsi produk seperti yang dilakukan kelas atas, menjadi cara membentuk gaya hidup kelas menengah untuk merasakan menjadi kelas atas. Reaksi yang ditimbulkan penonton dari konten Ria Ricis berhasil menanamkan hegemoni, bahwa kegiatan konsumsi merupakan sebuah gaya hidup, a way of life, sesuatu yang "natural" dan memang begitu adanya. Kendali hegemoni melalui penciptaan kesadaran umum yang memaksa subyek dikuasai, namun juga menciptakan kondisi dimana subjek merelakan dirinya untuk dikuasai (Muzairi, 2014), sehingga membuat pihak yang menghegemoni terus dominan. Wajar ketika, konten bertema Squishy dan belanja menjadi daya tarik dan banyak ditonton. Ketika konten banyak disukai, Ada kelompok yang menerima keuntungan dalam proses hegemonik dan dirugikan melalui proses persetujuan bukan paksaan (Hamid, 2013). Artinya kelompok dominan akan berkuasa, untuk terus memproduksi, seperti konten bertemakan Squishy dan belanja dengan berbagai egel.

\section{Media Mempertahankan ideologi}

Upaya mempertahankan idelogi media bukan perkara mudah, pasalnya audies memiliki refrensi pengetahuan akan realitas yang terus berubah, sehingga media akan terus memperbarui konten untuk mempertahankan idelologi. Begitupula ketika hegemoni budaya yang menekankan persetujuan dirasionalisasi terhadap dominasi seseorang. Di sini, ideologi tidak cukup, pembenaran yang dirasionalisasi berfungsi untuk 'memperbaiki' kontradiksi yang melekat dalam masyarakat dengan ketidaksetaraan hubungan sosial (Jaques et al., 2019), sehingga membutuhkan alat untuk membuat hegemoni tersebut menjadi dominan salah satunnya penggunaan bahasa. Bahasa tidak hanya mencerminkan kenyataan tetapi membangun realitas yang akan membentuk makna, identitas, objek dan subjek dibentuk melalui sistem praktik yang diwujudkan oleh wacana (Lears, 2016). Melalu wacana tersebut terus dipertahankan kedudukan. Konten Ria Ricis berusaha mempertahankan wacana idelogi konsumtif dengan praktek menunjukan kesenangan yang dianggap sebagai bentuk gaya anak muda untuk membentuk pengetahuan dan tindakan.

Penggunaan bahasa diperkuat dengan bahasa sederhana dan lebih keseharain yang mudah dipahami audiens. Upaya membuat sebuah produksi idelogi dilakukan secara natural sehingga audiens akan mudah menerima. Konten belanja dan Squishy dijadikan alat membangun idelogi konsumsi yang terus diulang dengan berbagai kemasan konten. Pengulang membentuk konsep sosial yang dasarnya pada peningkatan konsumsi sebagai gaya hidup. Konsep ini terus dibangun dengan melakukan reperesentasi sedekat mungkin dengan fenomena. Belanja sangat dekat dengan aktivitas keseharian yang dilakukan setiap orang, begitupula Squishy yang dekat dengan anak-anak remaja. Ria memanfatkan fenomenan tersebut yang direpresentasikan dalam kesehariannya melalui penekanan.

Menurut Moscovici (1988) dalam (Monaco dan Guimelli, 2011), ada tiga cara representasi bisa menjadi sosial. Pertama, representasi hegemonik yang dibagikan lintas grup dan berakar dalam budaya, dalam memori kolektif dalam kepercayaan yang dipegang secara luas. Konteks kasus, kelompok Ria Ricis terus mempetahankan 
konsep konsumsi (belanja warna-warni dan Squshy) sebagai identitas chanel yang akan membentuk perhatian dan konsep kebudayaan dalam kehidupan sosial. Kedua, representasi yang dibebaskan sebagai representasi dengan tingkat otonomi tertentu dengan menghormati segmen masyarakat yang berinteraksi. Interaksi di kolong komentar Youtube memungkinan produksi konten akan lebih bervariatif dan efektif untuk memberikan pengaruh, sehingga hal tersebut bentuk representasi dibebaskan yang diaktualisasikan dalam konten. Ketika media sedekat mungkin membangun interaksi dan tidak memberi jarak, makan kuasa akan mampu meminimalisir pertentangan.

Ketiga, representasi polemik sebagai representasi yang dihasilkan selama konflik sosial, kontroversi sosial, dan masyarakat secara keseluruhan. Representasi polemik terlibat dalam sosial perubahan dan inovasi. Chanel Ria Ricis dihadapi situasi reperesentasi polimik ketika konten yang menjadi andalan tidak menghadpi respon baik akan diganti begitupula sebaliknnya, misal konten belanja warna-warna menarik perhatian audiens lebih, sehingga memunculkan konten serupa dengan tema sama, seperti konten belanja warna merah.

Munculnya tema serupa berupaya mempertahankan idelogi dengan berbagai bentuk reperesentasi yang akan mempengaruhi tindakan sosial. Dalam mengekspresikan ideologi dukungan terhadap konten dimungkinkan dengan adannya digital media seperti Youtube melalui praktek alogaritma, sehingga akan mendominasi konten dalam layar "berada" di Youtube. Media baru sangat berbeda dengan media konvensional, yang hanya fokus pada interaksi satu arah. Pandangan Gramsci, bahwa hegemoni sebagai "persetujuan spontan" yang diberikan oleh massa besar penduduk kepada arahan umum yang dipaksakan pada kehidupan sosial oleh kelompok fundamental dominan (Lears, 2016). Paksaan di sini bentuknya halus tanpa ada unsur memaksa dalam waktu singkat, sedangkan persetujuan disebabkan oleh prestise konsekuen dari kepercayaan kepada kelompok dominan karena adanya posisi dan fungsi dalam produksi (chanel Youtube Ria RIcis). Reperesentaasi media tidak mencerminkan kenyataan apa adannya (Nasrulah, 2018), sehingga memungkinkan dikemas untuk kepentingan komersil dan mengalami penolakan. Artinya konten dengan tema serupa berkembang sangat dipengaruhi penonton yang menyaksikan. Kenyataannya kapitalisme menciptakannya kesadaran palsu, meskipun konsumen banyak yang sepenuhnya sadar dan kritis terhadap berbagai ketidaksetaraan dan ketidakadilan terkait dengan konsumerisme (Miles 156) dalam (Stavrakakis, 2006).

\section{SIMPULAN}

Akun Ria Ricis menghegemoni penonton dengan mengemas konten yang dekat dengan keseharian dengan pendekatan humoris untuk mengeblurkan pengaruh kekuasaan dalam menanamkan ideologi konsumtif. Ria Ricis mengandalakan konten belanja untuk menarik penonton untuk terlibat dalam konten yang akan berdampak pada keuntungan pribadi, Ria Ricis dengan 
konsep hegemoni yang mengarah pada budaya kesenangan mampu membuat orang tertarik dan menerima idologi konsumtif hal itu terlihat dari respon nitizen yang merespon baik konten. ekposur vidio dengan tema belanja sangat mempengaruhi penonton yang kebanyakan anak remaja. Dalam membangun kedekatan dengan realitas, video Ria dibangun dengan konsep keseharian dengan dukungan lingkungan yang didominasi interior mewah, yang akan memotivasi penonton ingin menjadi seperti aktor, membangun fantasi ideal tentang kehidupan kelas atas, dan menaturalkan konten yang mengarahkan pada kebutuhan seperti belanja. Oleh karena itu, gaya hidup konsumtif yang dihegemonikan Ria Ricis mampu membuat orang terhegemoni tanpa ada unsur paksaan dan tanpa sadar.

\section{DAFTAR PUSTAKA}

Daldal, A. (2014). Power and Ideology in Michel Foucault and Antonio Gramsci: A Comparative. American Research Institute for Policy Development, 2(2), 149-167.

Dimyati, I. (2014). Jeprut: Perlawanan terhadap Hegemoni Kekuasaan. Antropologi Indonesia O(75), 79-100. diunduh di https://doi.org/10.7454/ai.v0i75.352i1/tan ggal 12 Desember 2019

Eriyanto. (2011). Analisis Wacana Pengantar Analisis Teks Media. LKis.

ESTIANI, P. (2012). Hegemoni Gramsci Majalah Fashion Sebagai Penanaman Gaya Hidup Konsumerisme Kepada wanita. diunduh di Academia.Edu/ tanggal 12 desember 2019

Falah, F. (2018). Hegemoni Ideologi dalam Novel Ayat-Ayat Cinta Karya Habiburrahman el Shirazy (Kajian Hegemoni Gramsci). Nusa, 13(9), 351-360. diunduh di https://doi.org/10.1017/CB097811074153 24.004/ tanggal 12 desember 2019

Grégory Lo Monaco and Christian Guimelli. (2011). Hegemonic and Polemical Beliefs: Culture and Consumption in the Social Representation of Wine. The Spanish Journal of Psychology, 14(1), 237-250. diunduh di https://doi.org/10.5209/rev/ tanggal 11 desember 2019

Hamid, M. A. C. W. F. (2013). Teori Komunikasi Massa. Ghalia Indonesia.

Ida, R. (2018). Metode Penelitian Studi Media dan kajian Budaya (cetakan ke). Prenadamedia Group.

Jaques, C., Islar, M., \& Lord, G. (2019). Post-Truth: Hegemony on Social Media and Implications for Sustainability Communication. Sustainability, 11(7), 2120. diunduh di https://doi.org/10.3390/su11072120/ tanggal 12 desember 2019

Juditha, C. (2018). Social Media Hegemony: Gosip Instagram Account @Lambe_turah Hegemoni Media Sosial: Akun Gosip Instagram @Lambe_turah. Jurnal Penelitian Komunikasi Dan Opini Publik, 22(1), 16-30. diunduh https://jurnal.kominfo.go.id/index.p hp/jpkop/article/view/1339/884/ 6 desember 2019

Kellner, D., Hainsworth, S., \& Hall, S. (2003). Teori Media-Marxist : Sebuah Pengantar. 79-90.

Kertamukti, R., Nugroho, H., \& Wahyono, S. B. (2018). Komunikasi Visual: Fantasi Tubuh Wanita Kelas Menengah di Instagram. Jurnal Kajian Komunikasi, 6(2), 231. diunduh di https://doi.org/10.24198/jkk.v6i2.17925/ tanggal 11 desember 2019

Lears, T. J. J. (2016). The Concept of Cultural Hegemony: Problems and Possibilities Author ( s ): T . J . Jackson Lears Source: The American Historical Review, Vol . 90 , No . 3 ( Jun ., 1985 ), pp . 567-593 Published by: Oxford University Press on behalf of the American Hi. Oxford Journals, 90(3), 567593.

Mahdi, A. (2015). BERITA SEBAGAI REPRESENTASI IDEOLOGI MEDIA (Sebuah Telaah Kritis). AlHikmah, 9(2). diunduh di https://doi.org/10.24260/alhikmah.v9i2.324 tanggal 9 desember 2019

Mora, N. (2014). Reproduction of Patriarchal Hegemony in Media Texts. Electronic Journal of Social Sciences, 48, 131-148.

Mutiaz, I. R. (2019). Konstruksi Realitas Simbolik Generasi Milenial Melalui Tema Fantasi Selebgram Di Media Sosial. Jurnal Sosioteknologi, 18(1), 113-129. diunduh di https://doi.org/10.5614/sostek.itbj.2019.18 .1.9/ tanggal 7 desember 2019

Muzairi. (2014). Pergeseran Sistem Kekuasaan dari Marxisme Kehegemoni dan Politik Media. Esensia, 15(2), 25-26.

Nasrulah, R. (2018). Khalayak Media, Identitas, Ideologi dan Perilaku Pada Era Digital. Simbiosa Rekatama Media. 
Oktavianti, R. (2018). Reportase dalam Hegemoni Pemerintah dan Media: Studi Kasus Jurnalis Kepresidenan Era Soeharto dan Joko Widodo. Jurnal Komunikasi Indonesia, 5(1), 37-47. diunduh https://doi.org/10.7454/jki.v5i1.8331/ tanggal 12 desember 2019

Sa'diyah, S. S. (2019). Budaya Penggemar Di Era Digital (Studi Etnografi Virtual Pada Penggemar Bts Di Twitter). Jurnal Ilmu Komunikasi: JKOM, 2(1), 1-10. diunduh di https://doi.org/https://doi.org/10.33005/jk om.v2i1.34/ tanggal 6 desember 2019

Siswati, E. (2018). Anatomi Teori Hegemoni Antonio Gramsci. Translitera: Jurnal Kajian
Komunikasi Dan Studi Media, 5(1), 11-33. diunduh di https://doi.org/10.35457/translitera.v5i1.3 55/ tanggal 12 desember 2019

Stavrakakis, Y. (2006). Objects of Consumption, Causes of Desire: Consumerism and Advertising in Societies of Commanded Enjoyment. 83-106.

Yilmaz, M. (2014). The Effect of dominant ideology on media: The Syria Case. The European Journal of Social \& Behavioural Sciences, 10(3), 1527-1540. diunduh di https://doi.org/10.15405/ejsbs.136 / tanggal 11 desember 2019 